\title{
Foreign Language Teacher Recruitment: Theoretical Perspectives and Empirical Findings
}

\author{
Seyyed Ali Ostovar-Namaghi, Seyyedeh Mobina Hosseini \\ University of Shahrood, Shahrood, Iran
}

\begin{abstract}
In some contexts such as private language schools of Iran language teachers are recruited mainly on the basis of their speaking fluency and in other EFL contexts they are recruited simply because they are native speakers. Moreover, previous studies mainly focus on comparing the effectiveness of native and non-native language teachers by exploring learners' and teachers' perceptions of native and non-native language teachers. Since recruitment criteria are theoretically unjustified and the results of previous studies are subjective and inconclusive, this study aims at making a case in the opposite direction. That is, the researchers argue that there should be: (1) a shift away from recruiting language teachers on the basis of their speaking fluency and native language background towards hiring language teachers on the basis of their professional performance in the language classroom; (2) a shift away from exploring learners' and teachers' perceptions of native and non-native teachers towards studying the effect of teachers' native language on learners' proficiency, accuracy, fluency, and achievement. To pave the way for these shifts, this study first reviews the theoretical perspectives and empirical findings concerning effective language teachers and then draws conclusions and implications which help interested stakeholders, i.e., supervisors, make informed decisions when they recruit language teachers.
\end{abstract}

Keywords: teacher effectiveness, native language teachers, non-native language teachers, recruitment criteria

\section{Introduction}

When language teaching profession was in its infancy, there were no professionally trained teachers; hence, employers recruited language teachers on the basis of what Phillipson (1992) calls "native speaker fallacy". That is, it was wrongly supposed that native speakers are effective teachers simply because they know their language. Although language teaching profession has come of age and there are lots of professionally trained native and non-native language teachers, even today language teacher recruitment is still based on this fallacy. Still worse, in some contexts such as Iran many language schools hire teachers on the basis of teachers' speaking proficiency. That is, in some contexts professionally untrained teachers are recruited simply because they are native speakers while in some other contexts professionally untrained teachers are recruited simply because they can speak English fluently. This study aims at problematizing these recruitment criteria and making a case for recruiting professionally trained language teachers by presenting theoretical perspectives and empirical evidence which substantiate this position and provide interested stakeholders with a solid framework for language teacher recruitment.

Seyyed Ali Ostovar-Namaghi, Associate Professor of TEFL, Department of Applied Linguistics, University of Shahrood. Seyyedeh Mobina Hosseini, MATEFL Candidate, Department of Applied Linguistics, University of Shahrood. 


\section{Theoretical Perspectives}

Stronge and Hindman (2006) stated that one of the most critical elements in the success of any school is the quality of teaching that occurs every day in every classroom. If we want students to succeed to their maximum potential, having a qualified teacher working with every student is paramount. For this reason, recruiting, selecting, inducting, and sustaining highly effective teachers are the greatest challenges facing today's educational leaders (p. vii). However, recruiting effective teachers is not possible unless we know professional and personal traits that effective teachers should possess.

Many studies have tried to define who an effective teacher is (Anderson, 2004; Stronge, 2002; Anderson, 1991; Kounin, 1970; Rubio, 2009; Burton, 2000). Anderson (2004) stated that effective teachers are those who achieve goals which they set for themselves or which they have set for them by others. From another point of view, Stronge (2002) suggested that an effective teacher is the one who always produces a class of high-achievers, or a teacher who will be evaluated positively by supervisors and administrators. Similarly, Anderson (1991) believed that "...an effective teacher is one who quite consistently achieves goals which either directly or indirectly focuses on the learning of their students" (p. 18). In addition to this, effective language teachers have been described in the literature as having not only a profound competence in the target language but a set of personal qualities like sensitivity, warmth, and tolerance (Vadillio, 1999). By the same token, Burton (2000) holds the opinion that good teachers need to have knowledge, uniqueness, reciprocity, and professionalism. Since effective teachers should be good managers and handlers, Kounin (1970) defines "effective teachers" as those who "accurately handle inappropriate student behavior, manage competing or developing events more smoothly through instruction, maintain appropriate pacing, and maintain a group focus" (p. 49).

Similarly, Rubio (2009) defined an effective teacher as a perfectionist who is encouraging, approachable, caring, enthusiastic, affective, and understanding. According to Ethell and McMeniman (2000), effective teachers have a larger knowledge base from which to draw and usually organize their knowledge more efficiently in complex interconnected schemas and utilize it more effectively. They also believe that having both superior subject-matter knowledge and pedagogical knowledge is essential for successful teachers.

What makes a teacher effective has been a subject of importance for many educational scholars. Pettis (1997) identified three main characteristics for a professionally competent teacher. According to her, an effective teacher must firstly be principled and knowledgeable in addition to being skillful. Secondly, professional needs and interests of an effective language teacher must change over time and develop during his/her teaching. Thirdly, a teacher must be personally committed to his/her professional development. In another classification, Clark and Walsh (2002) categorized characteristics of an effective English language teacher into four clusters of discipline knowledge, pedagogical knowledge, knowledge of context, and personal knowledge. Owing to the fact that in English language teaching and learning some teachers are regarded as more successful than others, Brown (2001) believes successful teaching depends on the teachers' language proficiency, language-teaching skills, interpersonal communication ability, and personality. A checklist of good language-teacher characteristics is also offered by Brown (2001), which consists of four categories: technical knowledge, pedagogical skills, interpersonal skills, and personal qualities. On the other hand, focusing on intrinsic features, Ruiz-funes (2002) characterizes language teachers in terms of the love for the target language, attitude towards the profession and students, motivation and enthusiasm which should be apparent in potential 
EFL teachers. The foregoing traits can be used as a basis for teacher evaluation. Cullingford (1995) emphasized the fact that students are able to detect, as well as to analyze not only English language teachers' personalities, but also how far teachers have accepted their professional role.

Although one can find some consensus regarding traits of effective teachers, one issue remains controversial, i.e., "Who makes a better language teacher-native speakers or non-native speakers?" Throughout the history of language teaching, there has been a heated debate between scholars and practitioners about who is best suited for teaching English language, i.e., native or non-native English speaker teachers. While in fact the belief that a foreign language should be taught by a native speaker of the language is widespread, a considerable attention is given to non-native English teachers in the higher educational institutions in field of English language teaching. However, Wong (2009) asserted that many employers of private language centers and public school principals in non-English speaking countries, especially in Asia, have begun hiring native English teachers to teach at their centers or schools. Phillipson (1992) calls this ideology a "native speaker fallacy" to refer to unfair treatment of qualified non-native speakers (NNSs). He perceives that NNSs can acquire such attributes through teacher training. Having gone through the language learning process, they are more qualified to teach a language than native speakers.

Conversely, Stern (1983) favors native speakers by claiming that native speakers have (1) a subconscious knowledge of rules; (2) an intuitive grasp of meanings; (3) the ability to communicate within social settings; (4) a range of language skills; and (5) creativity of language use. Following this logic, a growing number of native English speakers, who have no teaching qualifications, have been hired as ESL teachers (Maum, 2001). Rejecting this professionally unjustified criterion, Maum (2002) pointed that one whose mother tongue is English cannot be considered as a qualified English teacher. Likewise, Canagarajah (1999) asserted that not all native speakers may make good teachers of their first language.

Despite the foregoing objections, native speakers enter the profession on the basis of their superior English competence (Samimy \& Brutt-Griffler, 1999). Shin (2008) stated that native speaker proficiency in the target language is not a sufficient qualification for such teaching positions. Rather, as Lasagabaster and Sierra (2002) state, a great deal of training and practice is required in language teaching. Regardless of their native language background, qualified ESL and EFL educators not only demonstrate a high level of written and oral proficiency in the English language, but also demonstrate teaching competency. Besides pedagogical challenges, there are also demographic challenges that render it impossible for all language teaching positions to be filled by teachers from native-English countries. Even if all native speakers were to be employed in ELT, they would not be enough to quench the fever-like quest for native-speaking teachers of English.

Instead of favoring one or the other, however, some scholars recognize both native language teachers and non-native ones by arguing that in an ideal EFL environment there should be a good balance between native and non-native language teachers (Medgyes, 1994). As many researchers believe, a kind of collaboration between native and non-native English teachers would be beneficial (Maum, 2001; Medgyes, 1992; Swales, 1993). In so doing, both sides of this continuum can complement each other in their strengths and weaknesses in various aspects such as linguistic, cultural, and educational backgrounds. For example, native English teachers are better aware of the appropriate contexts of language use but not necessarily in the "context of language learning" (Widdowson, 1994) while non-native language teachers, can explicitly explain rules and structure of language to the students, especially those teachers who share the same mother tongue with their students (Harmer, 1991). Along the same lines, Medgyes (1992) believes that native speakers have the 
advantage of being highly proficient in the target language, whereas non-native speaker teachers can serve as a good learning model for students. He also argues that non-native teachers, in addition to speaking the learners' L1, are able to share the difficulties they experienced and their learning strategies with learners.

While some scholars favor native English teachers and others argue for balancing the proportion of native and non-native language teachers, Medgyes (1994) favors non-native language teachers by asserting that non-native language teachers have much unique strength on the following grounds: (1) Since they have learned the language and attained a high label of proficiency in it, they can be considered as a good model for language learners; (2) Since they are consciously aware of the strategies they used to develop their proficiency, they can teach those strategies more effectively; (3) Because of their conscious knowledge, they are able to supply learners with more information about the English language; (4) Since they experienced the difficulties of learning a language, they can anticipate and prevent language difficulties of their students better; (5) Since they themselves have learned the language they teach, they are more likely to be more empathetic to the needs and problems of learners; and (6) Since they have the same language background as the students, they can use students' L1 to their advantage.

To sum up, based on the foregoing review, there are three arguments concerning the effectiveness of native and non-native language teachers: (1) native English teachers are more effective than non-native English teachers; (2) native and non-native teachers are equally effective and as such they should cooperate with each other in EFL contexts; and (3) non-native English teachers are more effective than native English teachers. This heated debate will never settle unless we acknowledge that an English teacher should be qualified in two dimensions: (1) s/he should know English and (2) s/he should know teaching. Along these lines, there should be a shift away from arguing whether effective teachers are native or non-native speakers towards arguing whether they are professionally trained or not, i.e., irrespective of whether language teachers are native or non-native speakers, they should be professionally trained in teaching English as a foreign language.

\section{Empirical Findings}

Instead of involving themselves in the endless and futile arguments concerning the comparative effectiveness of native and non-native language teachers, some scholars have tried to put their assumptions to test by collecting empirical evidence. Various scholars have tried to find out the most salient characteristics of effective English language teachers either from students' perceptions (Salahshour \& Hajizadeh, 2012; Chen, 2012; Arikan, Tasher, \& Sarach-Suzer, 2008; Mollica \& Nuessel, 1997; Feldman, 1976) or teachers' perceptions (Khojastemehr \& Takrimi, 2009; Lang, McKee, \& Conner, 1993; Witcher, Onwuegbuzie, \& Minor, 2001).

Some studies have tried to explore learners' perspectives concerning effective teachers. In a recent study, Salahshour \& Hajizadeh (2012) identified the main features of an effective EFL instructor based on language students' perspectives. Their quantitative research showed that effective teachers have an interest in their job, have a sense of responsibility towards their job, are enthusiastic and lively, are self-confident, and have knowledge of subject matter. In another study, Chen (2012) investigated the favorable and unfavorable characteristics of the EFL teachers as perceived by Thai university students. The characteristics were grouped into personal trait-related and classroom teaching-related characteristics. The personal trait-related characteristics included emotion, kindness, fairness, lenience, and responsibility and the classroom teaching-related characteristics were concerned with aspects of lesson delivery, language used in teaching, 
classroom activity organization, and classroom atmosphere creation. An interesting finding, according to Chen, was that some students favored teachers who spoke English and Thai in the classroom. Some students preferred teachers who could speak Thai. According to this study, if the teacher spoke English and Thai while teaching, they could understand the teaching better and would have higher motivation to learn.

Similarly, Arikan, Tasher, and Sarach-Suzer (2008) conceptualized Turkish EFL students' perceptions of an effective English language teacher. The results showed that effective teachers teach both formal and informal English, incorporate games into teaching, and organize group/pair work activities in the classroom. In addition, they favored teachers who use real life situations in the classroom effectively, but do not favor teachers with high teacher talking time. These students perceived foreign language teachers as ineffective if they: (1) heavily depended on their lesson plans; (2) did not employ a variety of methods; and (3) disregarded the needs of the learners.

In an attempt to discover characteristics favored by college students, Feldman (1976) analyzed 72 studies and found that effective teachers: stimulate interest in the learners; are clear and understandable; are knowledgeable in subject matter; are prepared and organized for the course and being enthusiastic about the subject matter and teaching. Friendliness, helpfulness, and openness to others' opinions were traits that students preferred in teachers, especially when they freely described their ideal or best teacher.

Chen and Lin (2009) investigated Chinese students' perceptions of the characteristics of effective EFL teachers. The results revealed that the instructional competence, personality, and teacher-student relationship aspects were all important to be an effective EFL teacher. However, personality and teacher-student relationship were considered more important than instructional competence. More recently, Barnes (2010) examined the students' beliefs about the features of effective EFL teachers. The results of the study were framed under five categories including rapport, delivery, fairness, knowledge and credibility, and organization and preparation. Students considered rapport and delivery as very important characteristics of an EFL teacher.

The foregoing empirical studies clearly show that learners evaluate their language teachers in terms of their professional competence and personality traits rather than their native language. Thus, the studies that give voice to learners' perspectives concerning effective teachers and effective teaching have clear implications for language teacher recruitment. It is true that language teachers are hired by employers and supervisors but it is the language learners who evaluate their efficacy; hence, instead of judging language teachers based on their native language, supervisors should evaluate language teachers in terms of their performance in the classroom.

Another group of researchers have tried to explore language teachers' perspectives on effective teaching performance. Khosjastemehr and Takrimi (2009) designed a study to identify teacher effectiveness factors according to the perceptions of English teachers in Khuzestan. The results indicated that, to these teachers, instructional strategies were viewed as more critical for teacher effectiveness than other characteristics.

Similarly, Witcher, Onwuegbuzie, and Minor (2001) examined pre-service teachers' perceptions of the characteristics of effective teachers by asking the participants to identify, rank, and define three to six characteristics that excellent teachers possessed. They found a total of 125 characteristics which were classified into the following six categories in order of endorsement rate: student-centeredness (79.5\%), enthusiasm for teaching $(40.2 \%)$, ethicalness $(38.8 \%)$, classroom and behavior management $(33.3 \%)$, teaching methodology $(32.4 \%)$, and knowledge of subject (31.5\%). Among the demographic variables, gender made the strongest contribution to the participants' responses with females endorsing learner-centeredness and males endorsing classroom and behavior management. In another study, Walls, Nardi, Von Minden, and Hoffman (2002) 
examined the perceptions of prospective, novice, and experienced teachers. The results yielded five dimensions in which effective and ineffective teachers differed. These dimensions are: (1) emotional environment; (2) teacher skill; (3) teacher motivation; (4) student participation; and (5) rules and grades.

Better results will be obtained if both students and teachers' perceptions on characteristics of an effective teacher were compared. Therefore, some researchers tried to make a comparison between these two groups to find the discrepancies on each side. To investigate the characteristics of effective English language teachers, Babai, Shishavan, and Sadeghi (2009) compared the perceptions of Iranian English language teachers and learners. The results indicated significant differences between teachers' and learners' views on some characteristics of effective English language teachers (EELTs). Teachers seemed to agree more strongly than students that an EELT should assign homework and integrate group activities into the classroom. Other areas of significant difference in opinions included preparing the lesson well, using lesson plans, and assessing what students have learned reasonably. On the contrary, students agreed more than teachers that teaching English in Persian (first language of the learners) was one of the prominent characteristics of an The qualitative analysis indicated that teachers perceived the features like mastery of the target language, good knowledge of pedagogy, and the use of particular techniques and methods, as well as a good personality to make an EELT, whereas, learners gave more weight to characteristics relating to a teacher's personality and the way he or she behaves in the classroom.

In a similar study, Park and Lee (2006) investigated the characteristics of effective EFL teachers as perceived by 169 teachers and 339 students in Korea with a self-report questionnaire consisting of three categories, i.e., English proficiency, pedagogical knowledge, and socio-affective skills. The results revealed that teachers perceived English proficiency the most important, whereas the students ranked pedagogical knowledge the highest. More recently, Wichadee (2010) investigated the characteristics of effective EFL teachers as perceived by 400 Bangkok University students and 53 full-time EFL teachers. The findings were organized in four categories, i.e., English proficiency, pedagogical knowledge, organization and communication skills, and socio-affective skills. The results showed that Bangkok University students defined effective EFL teachers as those with good preparation, effective communication ability, and a pleasant personality. This contrasted with the EFL teachers, who believed that having good English language proficiency was the most important for their job.

To sum up, a comparison of language teachers' perspectives with those of language learners clearly shows their conflict of interest. While teachers consider language proficiency as the main criterion for teaching effectiveness, learners focused on teaching performance and teachers' teaching skills. This difference in opinion clearly reflects local norms. Since language teacher recruitment is mainly based on language teacher proficiency in many contexts, this criterion has been normalized and language teachers have taken its truth value for granted. Language learners, however, are less concerned with teacher recruitment and more concerned with learning; hence, they take pedagogical skills as more determinant. Teachers do not just teach; rather they teach the students. As a consequence, it is learners' perspectives and priorities that should be taken into account in language teacher recruitment rather than teachers' perspectives.

Another group of researchers have tried to collect empirical evidence by comparing native and non-native language teachers. With this in mind, Medgyes (1992) conducted a study to compare native and non-native teachers. Questionnaires were distributed to those responsible for recruitment at English language teaching institutions in the UK in order to investigate the extent to which employers regarded being a native English 
speaker as an important criterion when making hiring decisions. $72.3 \%$ of the 90 respondents judged the "native English speaker criterion" to be either moderately or very important. Nonetheless, an overview of the results reveals that teaching qualifications, performance in interview, teaching experience, educational background, and recommendations are the most important criteria for recruiters.

Along the same lines, Wong (2009) conducted a case study of untrained ESL tutors and analysis revealed that: (1) The untrained native English teachers (NETs) tended to use authentic materials rather than traditional grammar textbooks and that most of them were very creative in lesson plans; (2) the untrained NETs were concerned about the length of the class and being incapable of explaining grammar and vocabulary; and (3) the confidence level of the untrained NETs in teaching gained immensely in a short period of time. In another study Ulate (2011) investigated insights towards native or non-native English teachers and found that a good language teacher is neither native nor non-native, but one that is professionally and personally prepared to perform the demanding task of educating others.

In a similar study, Al-Nawrasi (2013) investigated the effect of teachers' native language on students' achievement in speaking skills. The findings revealed that teachers' native language had no significant effect on students' overall speaking achievement test scores amongst 10th graders at $(\dot{\alpha}=0.05)$. However, the in-depth analysis showed that there was a significant correlation between native-ness and pronunciation in favor of the NESTs and a significant correlation between accuracy and native-ness in favor of the NNESTs.

Some researchers have explored students' perceptions of native or non-native English speaker teachers (Cheung, 2002; Samimy \& Brutt-Griffler, 1999; Torres, 2004; Lee, 2000). Samimy and Brutt-Griffler (1999) surveyed and interviewed 177 non-native graduate students. In addition to using a questionnaire they used classroom discussions, and in-depth interviews. They identified the NESTs as being informal, fluent, accurate, versatile, and flexible. Moreover, they used conversational and authentic English, provided positive feedback to students, and had communication as the goals of their teaching. Non-native English speaking teachers (NNESTs) were perceived as: relying on textbooks, applying differences between the first and second languages, being aware of negative transfer and psychological aspects of learning, being sensitive to the needs of students, being more efficient, knowing the students' background, and having exam preparation as the goal of their teaching. However, they did not consider the former to be superior to the latter.

Torres (2004) examined the preferences of 102 adult students for NESTs or NNESTs. The results indicated the students have a general preference for NESTs over NNESTs. They also have stronger preferences for NESTs in teaching specific skill areas such as pronunciation and writing. Similarly, Madrid (2004) carried out a study on 459 L2 learners to obtain a deeper insight into students' perceptions of the influence of native and non-native teachers on the English language classroom. The results of the study portrayed that students did not evince a preference for native teachers, whom they value as much as non-native ones. Nonetheless, as the students advance on to the higher grades, their preference for the native teacher also increases.

In a similar study, Alseweed (2012) conducted a study about university students' perception of the influence of native and non-native teachers. Quantitative and qualitative data were collected in two stages by means of students' questionnaires and interviews. The results revealed a statistically significant difference in the respondents' perceptions in favor of NESTs. Students showed more preference for NESTs as they go to higher levels. Students' previous learning experiences may affect their general preference for NESTs since they were taught by both types of teachers. Subjects also exhibited an explicit preference for NESTs in relation to the teaching strategies adopted. However, the respondents showed moderately favorable attitudes towards 
NNESTs who provide a serious learning environment and a favorable response to learners' needs.

In another study, Kelchand Santana-Williamson (2002) aimed to determine if ESL students could identify a native from a nonnative accent and if they held a more positive attitude towards teachers with "native" accents. The results showed that students were able to correctly identify native and nonnative speakers of English in only $45 \%$ of the occasions, and that their perception of the teachers' nativity strongly influenced the attitudes they held towards them. Additionally, teachers who were perceived as native speakers were seen as more likeable, educated, experienced, and overall better teachers, especially for speaking/listening skills. However, students also mentioned the importance of NNES teachers as role models, source of motivation, and language learners who understood students' learning difficulties.

Cheung (2002) indicated that Hong Kong university students made good comments on NETs' English proficiency, knowledge of the English speaking cultures, and skills in using English effectively. The subjects agreed that NNETs are good at grammar, have understanding towards their students as second language learners, and have common culture knowledge with them. In a similar vein, Mahboob (2004) showed that students view the speaking ability, lexical and culture knowledge as the strengths of NETs. However, in Walker's study (2001), NETs see their responsibility of being cultural consultants to be less important as language teachers. Instead, they see their teaching roles as improving students' oral skills. In a similar study, Walkinshaw and Oanh (2014) conducted a study about native and non-native English language teachers from student's perception. Students viewed NESTs as models of pronunciation and correct language use, as well as being repositories of cultural knowledge, but they also found NESTs poor at explaining grammar, and their different cultures created tension. Non-NESTs were perceived as good teachers of grammar, and had the ability to resort to the students' first language when necessary. Students found classroom interaction with non-NESTs easier because of their shared culture. Non-NESTs' pronunciation was often deemed inferior to that of NESTs, but also easier to comprehend. Some respondents advocated learning from both types of teachers, depending on learners' proficiency and the skill being taught.

To sum up, empirical findings can be categorized in to three sub-categories of personal qualities, professional qualities, and pedagogical skill. Personal qualities include language teachers' being friendly (Arikan, Tasher, \& Sarach-Suzer, 2008; Feldman, 1976), creative (Arikan, Tasher, \& Sarach-Suzer, 2008), enthusiastic (Salahshour \& Hajizadeh, 2012; Witcher, Onwuegbuzie, \& Minor, 2001); responsible (Salahshour \& Hajizadeh, 2012; Chen, 2012), young (Arikan, Tasher, \& Sarach-Suzer, 2008). Professional qualities include being either native or non-native English speaker (Ulate, 2011), giving homework (Shishavan \& Sadeghi, 2009); incorporating play games (Arikan, Tasher, \& Sarach-Suzer, 2008), teaching formal and informal English (Arikan, Tasher, \& Sarach-Suzer, 2008), using pair and group work (Chen, 2012; Arikan, Tasher, \& Sarach-Suzer, 2008). Finally, pedagogical skill include using visual material (Molica \& Nuessel,1997), having correct pronunciation (Arikan, Tasher, \& Sarach-Suzer, 2008), managing the classroom (Witcher, Onwuegbuzie, \& Minor, 2001), having subject matter knowledge (Salahshour \& Hajizadeh, 2012; Witcher, Onwuegbuzie, \& Minor, 2001).

\section{Implications for Practice}

Having reviewed the theoretical perspectives and the empirical findings related to effective teachers and native or non-native English language teachers, researchers found that the previous studies aimed at improving the practitioners' work. In the realm of practice, as far as the improvement of foreign language teaching is 
concerned, hopefully the results of this paper and those from a number of related studies may suggest new approaches to the process of language teachers' recruitment. Taking theories and empirical findings into account, it is suggested that supervisors should:

(1) be qualified enough to be the decision maker of the teacher selection process;

(2) consider a set of scientifically acceptable criteria in the process of teacher admission;

(3) incorporate various aspects of effective English language teachers in recruitment;

(4) have critical reasoning and analytical skill to distinguish the best applicants among others;

(5) leave their prejudice behind and consider all important skills related to an effective teacher.

Moreover, the study has precious implications for English language teachers. They:

(1) will be assessed based on the same criteria not supervisors' subjective judgments;

(2) can be well-prepared before applying for the job;

(3) can adopt characteristics of an effective English language and try to improve themselves based on these standards.

\section{Conclusion}

In the modern competitive world, employers and supervisors are willing to hire professionally qualified teachers. When they study theoretical perspectives, however, they find them inconclusive and contradictory. Moreover, they cannot hire teachers on the basis of claims, beliefs, and assumptions. Compared with theoretical perspectives, empirical findings provide a better basis for hiring and firing teachers. What is missing in the empirical findings, however, is experimental studies which explore the effect of teachers' native language on learners' language development; hence, though more promising, empirical findings are limited since they mainly explore teachers' and learners' perceptions of native and non-native English teachers rather than explore the effect of teachers' native language on learners' proficiency, fluency, accuracy and achievement. Thus, instead of judging teachers based on their native language, the field is in urgent need of experimental studies that study the differential effect of teachers' native language on learners' language development.

Moreover, following the discourse of professionalism, irrespective of their native language background both native English speaking teachers and non-native English speaking teachers should be professionally trained in TEFL before they enter the profession. Once certified, however, both groups are equally qualified to enter the profession. Thus, language teacher recruitment discourse needs a shift away from native speaker fallacy towards professionalism. If native English speaking teachers are qualified to teach English as a foreign or second language, they should be equally qualified to teach English as their first language. It goes without saying that native speakers who teach English in their home countries have gone through rigorous training program. When it comes to teaching English as a foreign language, they are welcomed to the profession on the basis of their speaking fluency. Not only is this practice professionally unjustified, it is ethically unacceptable because it goes without saying that a great many native speakers are illiterate in their own language.

\section{References}

Al-Nawrasi, O. (2013). The effect of native and nonnative English language teachers on secondary students' achievement in speaking skills. Jordan Journal of Educational Sciences, 9(2), 243-254.

Alseweed, M. (2012). University students' perceptions of the influence of native and non-native teachers. English Language Teaching, 5(12), 42-53.

Anderson, L. W. (1991). Increasing teacher effectiveness. Paris: UNESCO, International Institute for Educational Planning. 
Anderson, L. W. (2004). Increasing teacher effectiveness. In Fundamentals of educational planning. Paris: UNESCO.

Arikan, A., Tasher, D., \& Sarach-Suzer, H. (2008). The effective English language teacher from the perspective of Turkish preparatory school students. Education and Science, 33(150), 42-51.

Barnes, B. D. (2010). The attributes of effective lecturers of English as a foreign language as perceived by students in a Korean university. Australian Journal of Teacher Education, 35(1), 139-152.

Brown, D. (2001). Teaching by principles: An interactive approach to language pedagogy. New York: Addison Wesley.

Burton, J. (2000). Learning from teaching practice: A case study approach. Prospect, 15(3), 15-21.

Canagarajah, S. (1999). Interrogating the "native speaker fallacy": Non-linguistic roots, non-pedagogical results. In G. Braine (Ed.), Non-native educators in English language teaching (pp.77-92). Mahwah, NJ: Erlbaum.

Chen, J. (2012). Favorable and unfavorable characteristics of EFL teachers perceived by university students in Thailand. International Journal of English Linguistics, 2(1), 213-219.

Chen, Y., \& Lin, S. (2009). Exploring characteristics for effective EFL Teachers: From the perceptions of junior high school students in Tainan. STUT Journal of Humanities and Social Sciences, 2, 219-249.

Cheung, Y. L. (2002). The attitude of university students in Hong Kong towards native and non-native teachers of English (Master theses, The Chinese University of Hong Kong).

Chomsky, N. (1965). Aspects of the theory of syntax. Cambridge, Mass.: MIT Press.

Clark, J. C., \& Walsh, J. (2002). Elements of a model of effective teachers. Paper presented at AARE Conference, Brisbane.

Cullingford, C. (1995). The "effective" teacher. London: Cassell.

Darling-Hammond, L. (2002). The research and rhetoric on teacher certification: A response to "teacher certification reconsidered". Education Policy Analysis Archives, 10(36), 1-55.

Ethell, R. G., \& McMeniman, M. M. (2000). Unlocking the knowledge in action of an expert practitioner. Journal of Teacher Education, 51(2), 87-101.

Farmer, F. (2006).Accountable professional practice in ELT. ELT Journal, 60(2), 160-170.

Feldman, K. A. (1976). The superior college teacher from the students' view. Research in Higher Education, 5(3), 243-288.

Garcia, E. E. (1991). Effective instruction for language minority students: The teacher. Journal of Education, 173(2), $130-141$.

Harmer, J. (1991). The practice of English teaching. Harlow: Longman.

Kelch, K., \& Santana-Williamson, E. (2002). ESL students' attitudes towards native and non native speaking instructors' accents. CATESOL Journal, 14(1), 57-72.

Khojastemehr, R., \& Takrimi, A. (2009). Characteristics of effective teachers: Perceptions of the English teachers. Journal of Education and Psychology, 3(2), 53-66.

Kounin, J. S. (1970). Discipline and group management in classrooms. New York: Holt, Rinehart and Winston.

Lang, H., McKee, B., \& Conner, K. (1993). Characteristics of effective teachers: A descriptive study of the perceptions of faculty and deaf college students. American Annals of the Deaf, 138, 252-259.

Lasagabaster, D., \& Sierra, J. M. (2002). University students' perceptions of native and non-native speaker teachers of English. Language Awareness, 11(2).

Lee, I. (2000). Can a non-native English speaker be a good English teacher? TESOL Matters, 10(1), 19.

Madrid, D. (2004). Teacher and student preferences of native and nonnative foreign language teachers. Porta Linguarum, 2, 125-138.

Mahboob, A. (2004). Native or nonnative: What do students enrolled in an intensive English program think? In L. D. Kamhi-Stein (Ed.), Learning and teaching from experience: Perspectives on nonnative English-speaking professional. Ann Arbor, MI: The University of Michigan Press.

Maum, R. (2001). Non-native English speaking teachers in the English teaching profession. ERIC Digest.

Maum, R. (2002). Nonnative-English-speaking teachers in the English teaching profession. Washington, D.C.: Center for Applied Linguistics.

McKeachie, W. J. (1997). Wanting to be a good teacher: what have we learned to date? In J. L. Bess (Ed.), Teaching well and liking it: Motivating faculty to teach effectively. Baltimore: the Johns Hopkins University Press.

Medgyes, P. (1992). Native or non-native: Who's worth more? ELT Journal, 46(4), 340-349.

Medgyes, P. (1994). The non-native teacher. London: Macmillan.

Medgyes, P. (2001). When the teacher is a non-native speaker. In M. Celece-Murcia (Ed.), Teaching English as a second or foreign language (pp. 429-442). Boston: Heinle \& Heinle. 
Mollica, A., \& Nuessel, F. (1997). The good language learner and the good language teacher: A review of the literature. Mosaic, 4, $1-16$.

Nayar, P. B. (1994). Whose English is it? TESL-EJ, 1(1), F-1. Retrieved from http://www-writing.berkeley.edu/TESLEJ/ej01/f.1.html

Park, G., \& Lee, H. (2006). The characteristics of effective English teachers as perceived by high school teachers and students in Korea. Asia Pacific Education Review, 7(2), 236-248.

Pettis, J. (1997). Developing our professional competence: Some reflections. TESL Canada Journal, 16(2), 67-71.

Phillipson, R. (1992). Linguistic imperialism. Oxford: Oxford University Press.

Rubio, C. (2009). Effective teachers-Professional and personal skills. ENSAYOS, 24, 35-46.

Ruiz-funes, M. T. (2002). On teaching foreign languages: Linking theory to practice. London: Bergin \& Garvey.

Salahshour, N., \& Hajizadeh, N. (2012). Characteristics of effective EFL instructors: Language learners' perceptions. Procedia-Social Behavioral Sciences, 70, 163-173.

Samimy, K., \& Brutt-Griffler, J. (1999). To be a native or non-native speaker: perceptions of non-native students in a Graduate TESOL Program. In G. Braine (Ed.), Non-native educators in English language teaching (pp.127-144). London: Lawrence Erlbaum.

Samimy, K., \& Brutt-Griffler, J. (1999). To be a native or nonnative speaker: Perceptions of non-native students in a Graduate TESOL Program. In G. Braine (Ed.), Non-native educators in English language teaching (pp. 127-144). Mahwah, NJ: Lawrence Erlbaum.

Shin, S. (2008). Preparing non-native English-speaking ESL teachers. Teacher Development, 12(1), 57-65.

Shishavan, B. H., \& Sadeghi, K. (2009). Characteristics of an effective English language teacher as perceived by Iranian teachers and learners of English. English Language Teacher, 2(4), 130-143.

Stern, H. H. (1983). Fundamental concepts of language teaching. Oxford: Oxford University Press.

Stronge, J. H. (2002). Qualities of effective teachers. Washington DC: ASCD.

Stronge, J., \& Hindman, J. (2006). The teacher quality index: A protocol for teacher selection (Association for Supervision and Curriculum Development Alexandria, Virginia, USA).

Swales, J. (1993). The English language and its teachers: thoughts past, present and future. ELT Journal, 47(4), $283-291$.

Torres, J. (2004). Speaking up! Adult ESL students' perceptions of native and non-native English speaking teachers (Unpublished M.A. Thesis, University Of North Texas).

Ulate, N. (2011). Insights toward native and non-native ELT educators. Bellaterra Journal of Teaching \& Learning Language \& Literature, 4(1), 56-79.

Vadillio, R. S. M. (1999). Research on the good language teacher. EPOS, 15, 347-361.

Walker, E. (2001). Roles of native-speaker English teachers (NETs) in Hong Kong secondary schools. Asia Pacific Journal of Language in Education, 4(2), 51-77.

Walkingshaw, I., \& Oanh, D. H. (2014). Native and non-native English language teachers: Student perceptions in Vietnam and Japan. SAGE, 1-9.

Walls, R. T., Nardi, A. H., Von Minden, A. M., \& Hoffman, N. (2002). The characteristics of effective and ineffective teachers. Teacher Education Quarterly, 39-48.

Wichadee, S. (2010). Defining the effective English language teacher: Students' and teachers' perspectives. In A. M. Stoke (Ed.), JALT2009 Conference Proceedings. Tokyo: JALT.

Widdowson, H. G. (1994). The ownership of English. TESOL Quarterly, 28, 377-389.

Witcher, A., Onwuegbuzie, A., \& Minor, L. (2001). Characteristics of effective teachers: Perceptions of pre-service teachers. Research in the Schools, 8, 45-57.

Wong, C. Y. (2009). Are native speakers "good" language instructors? A case study of untrained ESL tutors. ARECLS, 6, 122-140. 